\title{
Prevalence of obsessive-compulsive disorder (OCD) among Iraqi undergraduate medical students in time of COVID-19 pandemic
}

Taqi Mohammed Jwad Taher ${ }^{1}$, Shaymaa Abdul Lateef Al-fadhul², Ali A. Abutiheen ${ }^{3}$, Hasanain Faisal Ghazi ${ }^{4^{*}}$ (D) and Naeem Shami Abood ${ }^{5}$

\begin{abstract}
Background: Obsessive-compulsive disorder (OCD) is a common mental disorder affecting millions of people. Its onset and peak are during late teens making university students a priority target. Medical student perhaps is at greater risk for developing OCD while corona COVID-19 is expected to more exaggerate symptoms mainly with extra hygiene and cleanliness practices. The aim of the study was to estimate the prevalence of OCD symptoms among Iraqi medical students, and to assess the associated psychological symptoms and its correlates. An analytic cross-sectional study was conducted among Iraqi medical students during the period from August to October 2020. An online anonymous, voluntary, and self-administered questionnaire based on the 18 questions ObsessiveCompulsive Inventory-Revised scale (OCl-R) was used to collect the data.

Results: A total of 1644 students had filled the questionnaire. Females were 1116 (67.9\%), while 1153 (70.1\%) had reported accompanying mental symptoms. Of which worry and stress were the most prevalent with 674 (25.9\%) and 617 (23.7\%) respectively. However, 707 (43\%) have probable OCD symptoms that need further assessment. Unpleasant thoughts were the most prevalent symptoms with 51.8\%. Surprisingly, the washing and contamination scales were low at $14 \%$ and $19.4 \%$ while repeating certain numbers was the least with $8 \%$. OCD symptoms were significantly related to younger age and earlier years of study. Further, all accompanied mental symptoms were significantly associated with probable OCD status.

Conclusion: High prevalence of OCD among medical students during the COVID-19 pandemic. No association of OCD with gender and family history. Younger students and early years of study were more likely to suffer from OCD symptoms.
\end{abstract}

Keywords: Obsessive-compulsive disorder (OCD), COVID-19 pandemic, Medical students, OCD symptoms, Iraq

\section{Background}

Obsessive-compulsive disorder (OCD) is a chronic psychiatric disorder. It causes unwanted thoughts (obsessions) and repetitive actions (compulsions). In their everyday lives, many people have concentrated on ideas

\footnotetext{
* Correspondence: dr.hasanainhabasha@gmail.com

${ }^{4}$ College of Nursing, Al-Bayan University, Baghdad, Iraq

Full list of author information is available at the end of the article
}

and repetitive acts. But, for people with OCD, the thoughts are more recurring, and the repetitive behaviors are over and cannot be ignored that they can disrupt their life [1-4].

Obsessive-compulsive disorder (OCD) is reported to be the fourth most frequent mental disorder worldwide $[5,6]$. OCD prevalence varies over age, regions, and others. However, OCD lifetime prevalence is estimated to be $2.3 \%$ ranging from $1.1-3.3 \%$. Some researchers

\section{Springer Open}

(0) The Author(s). 2021 Open Access This article is licensed under a Creative Commons Attribution 4.0 International License, which permits use, sharing, adaptation, distribution and reproduction in any medium or format, as long as you give appropriate credit to the original author(s) and the source, provide a link to the Creative Commons licence, and indicate if changes were made. The images or other third party material in this article are included in the article's Creative Commons licence, unless indicated otherwise in a credit line to the material. If material is not included in the article's Creative Commons licence and your intended use is not permitted by statutory regulation or exceeds the permitted use, you will need to obtain permission directly from the copyright holder. To view a copy of this licence, visit http://creativecommons.org/licenses/by/4.0/. 
indicated that OCD affects females slightly higher than males but other does not $[1,2,3,7,8]$.

Patients with OCD can have one or more groups of OCD symptoms. These symptoms can include an obsession with contamination washing rituals, frequent checking, persistent nasty or religious thoughts, redundant hoarding, uniformity and ordering, and others. However, these symptoms and attitudes are unsteady and tend to disappear for a period and return or change in their categories throughout the disease $[7,9,10,11]$.

While the exact causes of OCD are unclear and vary between genetic, environmental, and neurobiological factors. Patients with OCD might be with other co-existing mental hazards such as anxiety disorder, post-traumatic stress disorder, depression, substance use, eating disorder, learning, and suicidal thoughts [2, 8, 12].

Diagnosis of OCD is so difficult, not just because of the overlap of symptoms with other psychiatric disorders and diseases. But also, because many patients deny and not confirm the symptoms and ill behaviors they have encountered for numerous reasons, including the stigmatization of such mental diseases. And this raises the need for screening for OCD and OCD symptoms among patients with other mental disorders and risky groups including university students $[2,13,14]$.

As the onset of OCD develops mainly during adolescence and late teens with a median age of onset of 19-20 years. That makes high school and university students a remarkable target for screening for OCD and OCD symptoms. Further, studies reported double rates of OCD among university students in comparison to their rates among the general population. Furthermore, this age group is more prone to other mental hazards including substance use and suicidal attempts that are explained to be associated comorbidities for OCD [2, 13, 15, 16].

Undergraduate Medical students are at an increased risk for OCD, due to the stressful nature of medical schools as part of the heavy curriculum, less leisure time, as well that medical students are taught, trained, and asked to be more precise, perfect, and obsessive a little bit more. On the other hand, OCD can adversely affect academic performance, general well-being, social interaction, and suicidal thoughts. Issues that might have a huge impact on life unless being diagnosed early and properly managed $[4,6,11,12,17]$.

Corona COVID-19 pandemic is the biggest health challenge faced by the world in recent history. Affecting most countries with more than 42 million registered cases and over 1.150 .000 deaths reported death till October 25. Iraq reported the highest number of cases and deaths among Arab countries, with more than 450 thousand cases and more than 10 thousand deaths.
Corona COVID-19 pandemic is expected to have a negative effect on OCD patients and medical students firstly as a general stressor on health and communities, secondly by the closure of medical schools and the shifting toward online learning, and lastly by the increasing efforts of handwashing and general hygiene as an essential step in COVID-19 prevention which might trigger the obsession with contamination and compulsive washing of hands. Which are reported as the most common symptoms of OCD $[18,19,20]$.

So, this study aims to estimate the prevalence of the suggestive symptom of obsessive-compulsive disorder (OCD) among a sample of medical students in Iraqi universities during the COVID-19 pandemic era and to assess the associated psychological symptoms. In addition to the association of the probability of being OCD with the related sociodemographic features and other psychological symptoms.

\section{Methods}

An analytic cross-sectional study. This study was conducted among Iraqi medical students during the period from August 2020 to October 2020. The population of the study included all medical students attending different Iraqi universities except Kurdistan (north of Iraq). A convenient sample was included in this study. Data were collected by a structured questionnaire submitted online through different groups for medical students including Facebook, telegram, and WhatsApp groups for 2 weeks period. The questionnaire consisted of three parts: the first was containing sociodemographic features and associated risk factors, the second part consisted of 18 items from the Obsessive-Compulsive Inventory-Revised scale (OCI-R) [21], and the third part contains the summation of the final score of the participant. The questionnaire was translated from English to the Arabic language by a language specialist and pretested on 25 medical students who were excluded from the final analysis.

The OCI-R is a reduced form of the original OCI that consisted of 18 subjective questions that can be used for screening of OCD but it never gives a definite diagnosis. It can define the probable cases during the last month. The answer for each question consisted of the Likert scale (not at all, a little, moderately, a lot, and extremely) which coded from 0-4 respectively with a maximum total of 72, score more than 27 was considered as a probable OCD [4].

All 18 questions are used for the assessment of six types of symptoms related to OCD, including checking, hoarding, neutralizing, obsessing, ordering, and washing. The Arabic version for OCI-R was tested for validity and reliability in a previous study conducted in Saudi Arabia [22]. 
An official agreement was taken from the ethical approval committee. All participant students were consented to participate in a questionnaire filling with confidentiality. Students had the ability to scoring their symptoms to know if they are probably having OCD to be diagnosed as early as possible and seek medical advice and treatment.

Data were entered and analyzed by SPSS version 23 . Descriptive statistics were used by the mean and standard deviation for numerical data, while categorical data were represented by frequency tables. Association between categorical variables was performed by the chisquare test and the difference between means was performed by $t$ test for independent samples considering $p$ value equal or less than 0.05 as significant.

\section{Results}

The total sample size involved in this study was 1644 medical students who were willing to participate in this survey and answered the questionnaire through 2 weeks period from 19 August-2 September 2020. The sociodemographic features of participants and family history are presented in Table 1.

According to the results mentioned in Table 1, more than two-thirds (67.9\%) of the participants were females, only $3.5 \%$ were married, around one-third $(32.3 \%)$ are from the first stage. The higher response rate was among students living in Najaf and Karbala (25.9\% and 20.3\%) respectively. Less than one quarter $(21.5 \%)$ mentioned that they have a family member suffering from OCD.

The psychological and mental symptoms were reported from $1153(70.1 \%)$ of the participants as shown in Table 2. The majority of students mentioned symptoms of worry and stress in $58.5 \%$ and $53.5 \%$ in the same order.

According to OCI-R, the mean score for all students is found as $(27.3 \pm 12.4)$. There were $937(57 \%)$ of them probably normal persons, while $707(43 \%)$ of them were probably having OCD and need for further assessment for a definite diagnosis as shown in Fig. 1.

The frequency distribution of student's answers for the 18 items related to OCI-R score was presented in Table 3. Regarding the items that represented obsessing symptoms, the highest percentage of students answered, "extremely or a lot of" was $51.8 \%$ for the item "I am upset by unpleasant thoughts that come into my mind against my will" followed by $42 \%$ for the item "I frequently get nasty thoughts and have difficulty in getting rid of them." There were $29.6 \%$ of students said that they were extremely, or a lot of times check things more often than necessary which represented the higher percentage among items related to checking. About $28 \%$ of students mentioned they suffered from hoarding symptoms related to OCD which is "I avoid throwing things
Table 1 Frequency distribution of socio-demographic features of the study participants

\begin{tabular}{|c|c|c|}
\hline Categorical variables & Frequency & Percent \\
\hline \multicolumn{3}{|l|}{ Gender } \\
\hline Male & 528 & 32.1 \\
\hline Female & 1116 & 67.9 \\
\hline \multicolumn{3}{|l|}{ Marital status } \\
\hline Single & 1586 & 96.5 \\
\hline Married & 58 & 3.5 \\
\hline \multicolumn{3}{|l|}{ College stages } \\
\hline First stage & 531 & 32.3 \\
\hline Second stage & 327 & 19.9 \\
\hline Third stage & 336 & 20.4 \\
\hline Fourth stage & 199 & 12.1 \\
\hline Fifth stage & 133 & 8.1 \\
\hline Sixth stage & 118 & 7.2 \\
\hline \multicolumn{3}{|l|}{ Place of living } \\
\hline Baghdad & 186 & 11.3 \\
\hline Wasit & 285 & 17.3 \\
\hline Karbala & 333 & 20.3 \\
\hline Thi-qar & 111 & 6.8 \\
\hline Nineveh & 2 & 0.1 \\
\hline Qadisiyyah & 60 & 3.6 \\
\hline Babil & 82 & 5.0 \\
\hline Najaf & 425 & 25.9 \\
\hline Muthanna & 19 & 1.2 \\
\hline Maysan & 6 & 0.4 \\
\hline Diyala & 19 & 1.2 \\
\hline Basra & 103 & 6.3 \\
\hline Al Anbar & 6 & 0.4 \\
\hline Saladin & 3 & 0.2 \\
\hline Sulaymaniyah & 2 & 0.1 \\
\hline Erbil & 1 & 0.1 \\
\hline Kirkuk & 1 & 0.1 \\
\hline \multicolumn{3}{|l|}{ Family history of OCD } \\
\hline No & 1291 & 78.5 \\
\hline Yes & 353 & 21.5 \\
\hline Continuous variables & Mean & Standard deviation \\
\hline Age of participants (years) & 20.73 & 1.83 \\
\hline Number of sleep hours & 8.11 & 1.85 \\
\hline
\end{tabular}

away because I am afraid, I might need them later." Near half (40.9) of students were extremely or a lot upset if objects are not arranged properly which is one of the ordering subscales of OCI-R. Only $19.4 \%$ of the students had to wash or clean themselves simply because they feel 
Table 2 Frequency distribution of other psychological symptoms among the study sample

\begin{tabular}{lll}
\hline $\begin{array}{l}\text { Associated } \\
\text { psychological } \\
\text { symptoms }\end{array}$ & Responses \\
\cline { 2 - 3 } & $\boldsymbol{N}$ & Percent \\
\hline Worry & 674 & $25.9 \%$ \\
Depression & 465 & $17.9 \%$ \\
Drug abuse & 2 & $0.1 \%$ \\
Sleeping disorders & 476 & $18.3 \%$ \\
Feeding disorders & 283 & $10.9 \%$ \\
Stress & 617 & $23.7 \%$ \\
Other & 84 & $3.2 \%$ \\
Total & 2601 & $100.0 \%$ \\
\hline
\end{tabular}

they were contaminated (washing subscale). For the neutralizing subscale of OCI-R, there were only $15.9 \%$ of students extremely or a lot of felt that there are good and bad numbers. The mean $\pm \mathrm{SD}$ for each of the hoarding, checking, ordering, neutralizing, washing, and obsessing symptoms were $1.2 \pm 0.8,1.5 \pm 0.9,1.9 \pm 0.9$, $0.9 \pm 0.8,1.2 \pm 0.9$, and $2.0 \pm 1.1$ in the same order.

There was a significant association between both groups of students with college class $(p<0.001)$ and significant differences with age $(p<0.02)$. The presence of other psychological symptoms like worry, depression, sleeping disorders, feeding disorders, and stress was significantly associated with the probable OCD $(p<0.001)$. More than one-third of students (34.5\%) of the probable OCD group were from the first medical year. About $50 \%$ and $46.5 \%$ of students with symptoms suggesting OCD was suffering from worry and stress respectively.

\section{Discussion}

This is one of the scarce worldwide studies conducted for assessment of OCD and investigation of associated psychological symptoms, and sociodemographic features (Table 4). To our knowledge, there are no previous studies conducted in Iraq for estimation of the prevalence of OCD among the general population, meanwhile medical students during the COVID-19 outbreak. Current results showed that more than two-thirds of the responders are females, and this agrees with a similar female predominance in medical colleges. The prevalence of probable OCD in this sample is $43 \%$. This is higher than the prevalence reported from a previous study conducted on 200 medical students at the University of Sulaimani in Iraq, which was 6\% [23]. Earlier studies conducted among medical students in different countries reported lower prevalence ranged from 3.8 to $35.8 \%$ [4, 9, 24]. The current high prevalence is in congruence with an online survey of 6041 Canadian participants, in which a significantly higher prevalence of OCD symptoms during COVID-19 pandemic by 10-13 folds than pre-pandemic period [25].

Concerning associated psychological symptoms, lots of students reported having different psychological symptoms including worry then stress, sleeping disorders, and depression. Similar to current results, studies conducted in China, and Italy [26-28] indicated moderate to severe psychological impact of the COVID-19 pandemic with a higher rate of distress, anxiety, and depression among participants.

It was found that probable OCD was significantly associated with symptoms of either of worry, stress, depression, sleeping, and feeding disorders $(p<0.001)$. Correlation of OCD with stress, anxiety, and depression symptoms was reported by previous similar studies [4,

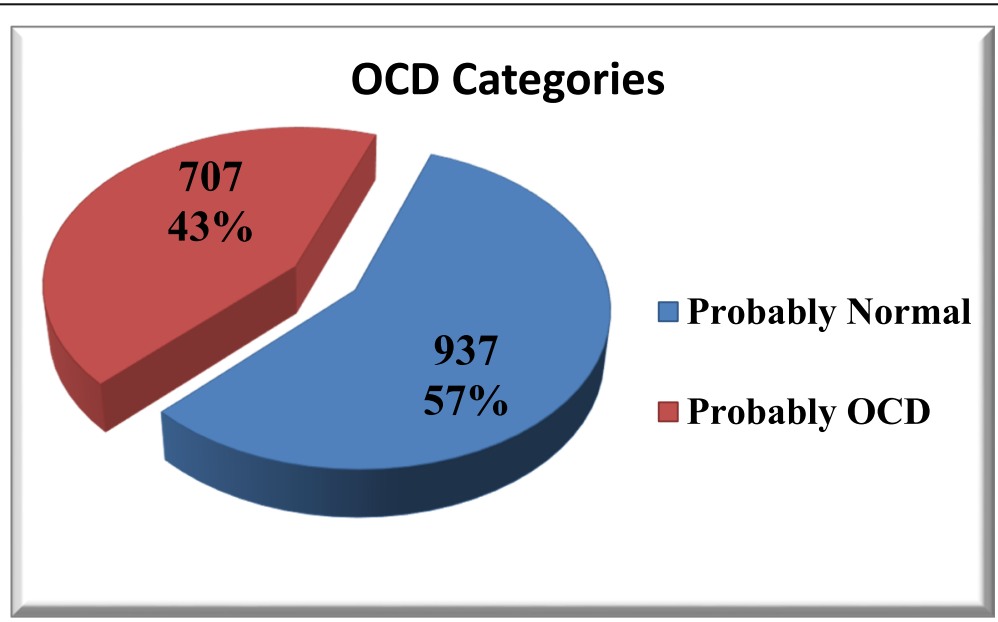

Fig. 1 Frequency distribution of OCD categories among participant students 
Table 3 Frequency distribution of the participant's answers for OCl-R score items

\begin{tabular}{|c|c|c|c|c|c|}
\hline Questions & $\begin{array}{l}\text { Not at all } \\
\text { No. (\%) }\end{array}$ & $\begin{array}{l}\text { A little } \\
\text { No. (\%) }\end{array}$ & $\begin{array}{l}\text { Moderately } \\
\text { No. (\%) }\end{array}$ & $\begin{array}{l}\text { A lot } \\
\text { No. (\%) }\end{array}$ & $\begin{array}{l}\text { Extremely } \\
\text { No. (\%) }\end{array}$ \\
\hline I have saved up so many things that they get in the way. & $592(36)$ & $559(34)$ & $343(20.9)$ & $138(8.4)$ & $12(0.7)$ \\
\hline I check things more often than necessary. & $102(6.2)$ & $409(24.9)$ & $482(29.3)$ & $481(29.3)$ & $170(10.3)$ \\
\hline I get upset if objects are not arranged properly. & $158(9.6)$ & $389(23.7)$ & $424(25.8)$ & $505(30.7)$ & $168(10.2)$ \\
\hline I feel compelled to count while I am doing things. & $751(45.7)$ & $382(23.2)$ & $283(17.2)$ & $189(11.5)$ & $39(2.4)$ \\
\hline $\begin{array}{l}\text { I find it difficult to touch an object when I know it has } \\
\text { been touched by strangers or certain people. }\end{array}$ & $557(33.9)$ & $538(32.7)$ & $280(17)$ & $189(11.5)$ & $80(4.9)$ \\
\hline I find it difficult to control my own thoughts. & $267(16.2)$ & $491(29.9)$ & $334(20.3)$ & $358(21.8)$ & $194(11.8)$ \\
\hline I collect things I do not need. & $571(34.7)$ & $568(34.5)$ & $319(19.4)$ & $158(9.6)$ & $28(1.7)$ \\
\hline I repeatedly check doors, windows, drawers, etc. & $512(31.1)$ & $486(29.6)$ & $344(20.9)$ & $214(13)$ & $88(5.4)$ \\
\hline I get upset if others change the way I have arranged things. & $197(12)$ & $454(27.6)$ & $328(20)$ & $451(27.4)$ & $214(13)$ \\
\hline I feel I have to repeat certain numbers. & $933(56.8)$ & $350(21.3)$ & $229(13.9)$ & $97(5.9)$ & $35(2.1)$ \\
\hline $\begin{array}{l}\text { I sometimes have to wash or clean myself simply because } \\
\text { I feel contaminated. }\end{array}$ & $449(27.3)$ & $483(29.4)$ & $393(23.9)$ & $236(14.4)$ & $83(5)$ \\
\hline $\begin{array}{l}\text { I am upset by unpleasant thoughts that come into my mind } \\
\text { against my will. }\end{array}$ & $159(9.7)$ & $378(23)$ & $255(15.5)$ & $502(30.5)$ & $350(21.3)$ \\
\hline $\begin{array}{l}\text { I avoid throwing things away because I am afraid I might } \\
\text { need them later. }\end{array}$ & $275(16.7)$ & $439(26.7)$ & $469(28.5)$ & $352(21.4)$ & $109(6.6)$ \\
\hline $\begin{array}{l}\text { I repeatedly check gas and water taps and light switches after } \\
\text { turning them off. }\end{array}$ & $622(37.8)$ & $478(29.1)$ & $282(17.2)$ & $185(11.3)$ & $77(4.7)$ \\
\hline I need things to be arranged in a particular way. & $252(15.3)$ & $460(28)$ & $520(31.6)$ & $332(20.2)$ & $80(4.9)$ \\
\hline I feel that there are good and bad numbers. & $737(44.8)$ & $358(21.8)$ & $288(17.5)$ & $189(11.5)$ & $72(4.4)$ \\
\hline I wash my hands more often and longer than necessary. & $614(37.3)$ & $425(25.9)$ & $408(24.8)$ & $140(8.5)$ & $57(3.5)$ \\
\hline $\begin{array}{l}\text { I frequently get nasty thoughts and have difficulty in getting } \\
\text { rid of them. }\end{array}$ & $183(11.1)$ & $464(28.2)$ & $308(18.7)$ & $407(24.8)$ & $282(17.2)$ \\
\hline
\end{tabular}

24, 25]. People with OCD often have other psychological comorbidities. Many of them have a lifetime diagnosis of a depressive or bipolar disorder $(63 \%)$ or an anxiety disorder (76\%) [29].

At this point, we should consider the role of COVID-19 as stressors that lead to a higher prevalence of OCD as well as other psychological symptoms, in addition to that medical students have a relatively higher prevalence of mental health problems than the general population as reported by metaanalytic studies [30, 31].

Current results showed that probably OCD students significantly younger than probably normal students $(p<$ 0.002), meanwhile more than one-third (34.5\%) of probably OCD students were from the first stages. Statistically, there is a highly significant association between OCD and college years $(p<0.001)$; this aligns with the previous study conducted among Brazilian medical students [4]; the authors demonstrated that severe obsessive-compulsive symptoms were associated with being in the first year, having depressive symptoms and difficulty in adaptation. Whereas other studies [9, 23] showed a non-significant relationship between age and OCD.
In this study, statistical analysis showed that there was no significant gender difference according to the presence of OCD, although females had higher than males with probable OCD (69.4\% vs $30.6 \%)$. Current results on gender are consistent with the findings of other researchers $[4,9,24]$.

Considering the presence of a family history of OCD, $23.6 \%$ of probable OCD students reported positive family history versus $19.9 \%$ of probably normal students; however, a non-significant association was found between family history and OCD frequency. This is in contrast to the finding of other authors $[9,23]$ who stated that a family history of OCD was more reported from students with OCD than from normal ones. This finding could be explained by the presence of additional environmental stressors which were triggered recent OCD cases rather than genetic factors. The results of this study showed a higher mean of OCD symptoms among the participants was an obsession. Likewise, Jaisoorya et al. [8] found a higher proportion of Indian college students with OCD reported obsessions. Whereas Torres et al. [4] reported a higher mean of OCD student was an ordering. 
Table 4 Frequency distribution and association of probably normal and OCD among different socio-demographic features

\begin{tabular}{|c|c|c|c|}
\hline Variables & Probably normal students $(N=937)$ & Probably OCD students $(N=707)$ & $p$ value \\
\hline Agelyears (mean \pm SD) & $20.8 \pm 1.8$ & $20.5 \pm 1.7$ & 0.002 \\
\hline Numbers of sleep hours (mean \pm SD) & $8.1 \pm 1.7$ & $8.1 \pm 2.0$ & 0.81 \\
\hline Gender & $N(\%)$ & $N(\%)$ & \\
\hline Males & $312(33.3)$ & $216(30.6)$ & 0.23 \\
\hline Females & $625(66.7)$ & $491(69.4)$ & \\
\hline \multicolumn{4}{|l|}{ Marital status } \\
\hline Single & $902(96.3)$ & $684(96.7)$ & 0.6 \\
\hline Married & $35(3.7)$ & $23(3.3)$ & \\
\hline \multicolumn{4}{|l|}{ College years } \\
\hline First year & $287(30.6)$ & $244(34.5)$ & $<0.001$ \\
\hline Second year & $169(18)$ & $158(22.3)$ & \\
\hline Third year & $177(18.9)$ & $159(22.5)$ & \\
\hline Fourth year & $136(14.5)$ & $63(8.9)$ & \\
\hline Fifth year & $88(9.4)$ & $45(6.4)$ & \\
\hline Sixth year & $80(8.5)$ & $38(5.4)$ & \\
\hline \multicolumn{4}{|l|}{ Family history of OCD } \\
\hline Yes & $186(19.9)$ & $167(23.6)$ & 0.06 \\
\hline No & $751(80.1)$ & $540(76.4)$ & \\
\hline \multicolumn{4}{|c|}{ Presence of other psychological symptoms } \\
\hline Worry & $319(34)$ & $355(50.2)$ & $<0.001$ \\
\hline Depression & $212(22.6)$ & $253(35.8)$ & $<0.001$ \\
\hline Drug abuse & $0(0)$ & $2(0.3)$ & 0.1 \\
\hline Sleeping disorders & $227(24.2)$ & $249(35.2)$ & $<0.001$ \\
\hline Feeding disorders & $126(13.4)$ & $157(22.2)$ & $<0.001$ \\
\hline Stress & $288(30.7)$ & $329(46.5)$ & $<0.001$ \\
\hline
\end{tabular}

\section{Limitations}

This study had some limitations. First, the diagnosis of OCD depended on the self-reported responses of students. No clinical interview was followed to confirm the diagnosis. Second, this study was crosssectional in design; therefore, the causal association cannot be ascertained. Third, the sampling method was convenient; this may limit the generalization of results. Lastly, the pandemic cannot be confirmed as the exact causes of OCD, so that longitudinal researches are necessary for confirming the pandemic effect on the psychological well-being of students. However, regardless of these limitations, the current study included a large sample size from different Iraqi cities; a well-validated instrument had been used to minimize information bias. The prevalence of OCD and its associated factors was evaluated for the first time during the COVID-19 outbreak among medical students.

\section{Conclusion}

This study demonstrates a high prevalence of OCD among medical students during the COVID-19 outbreak. Students with OCD have significant psychological symptoms. The results suggest no association of OCD with gender and family history. Younger students are more likely to suffer from OCD. Symptoms of OCD often hidden, negatively influence many life aspects of these students, therefore, efforts should be made by the college deanery to early identify and treat this condition. Further studies are recommended to measure the psychological impact of the pandemic on other college students and the general population.

Abbreviations

OCD: Obsessive-compulsive disorder; OCI-R: Obsessive-Compulsive InventoryRevised scale; COVID-19: Coronavirus disease

Acknowledgements 


\section{Consent for participation}

A written consent was taken from all participants before proceeding to answer the questionnaires. Participants need to read all the instructions and agree to participate in the study.

\section{Authors' contributions}

TMJT: formulate the idea and conduct the study, SALA: draft the manuscript, AAA: data collection, HFG: data analysis and results presentation, NSA: discussion and conclusion. All authors have read and approved the manuscript.

\section{Funding}

None

\section{Availability of data and materials}

Available on request

\section{Ethics approval and consent to participate}

Ethics approval was obtained from the Medical Research Bioethical Committee, College of Medicine/University of Kerbala, reference no:03-2020.

\section{Consent for publication}

NA

\section{Competing interests}

None

\section{Author details}

'Department of Family and Community Medicine, College of Medicine, Wasit University, Kut, Iraq. ${ }^{2}$ Department of Family and Community Medicine, College of Medicine, University of Kufa, Kufa, Iraq. ${ }^{3}$ Department of Family and Community Medicine, College of Medicine, University of Kerbala, Kerbala, Iraq. ${ }^{4}$ College of Nursing, Al-Bayan University, Baghdad, Iraq. ${ }^{5}$ Department of Psychiatry, Al-Zahraa Teaching Hospital, Wasit Health Directorate, Kut, Iraq

\section{Received: 18 December 2020 Accepted: 18 January 2021}

\section{Published online: 08 February 2021}

\section{References}

1. American Psychiatric Association, Obsessive-Compulsive Disorder (OCD), last updated July 2017. Accessed at 22-10-2020. Available at: https://www. psychiatry.org/patients-families/ocd/what-is-obsessive-compulsive-disorder

2. Fenske JN, Petersen K (2015) Obsessive-compulsive disorder: diagnosis and management. American family physician. 92(10):896-903

3. Pallanti S, Salerno $L$ (2020) The burden of adult ADHD in comorbid psychiatric and neurological disorders. Basil: Springer International Publishing $A G$

4. Torres AR, Cruz BL, Vicentini HC, Lima MC, Ramos-Cerqueira AT (2016) Obsessive-compulsive symptoms in medical students: prevalence, severity, and correlates. Academic Psychiatry. 40(1):46-54

5. Asghar MA, Rehman AA, Shafiq Y, Siddiq A, Zehravi M, Khan K, Asghar MA Abedin S (2020) Relationship of obsessive-compulsive disorders with religion and psychosocial attitude among local medical college students of Karachi: an epidemiological study. JPMA 70:1563

6. Ansari E, Mishra S, Tripathi A, Kar SK, Dalal PK (2020) Cross-sectional study of internalised stigma and medication adherence in patients with obsessive compulsive disorder. Gen Psychiatr 33(2):e100180

7. Raynal P, Melioli T, Chabrol H (2019) Personality disorder traits in young adults with subclinical obsessive-compulsive symptoms: not just traits related to obsessive-compulsive personality. Bulletin of the Menninge Clinic. 83(4):433-452

8. Jaisoorya TS, Reddy YJ, Nair BS, Rani A, Menon PG, Revamma M, Jeevan CR, Radhakrishnan KS, Jose V, Thennarasu K (2017) Prevalence and correlates of obsessive-compulsive disorder and subthreshold obsessivecompulsive disorder among college students in Kerala, India. Indian J Psychiatr. 59(1):56

9. Assareh M, Rakhshani T, Kashfi M, Ayazi M (2016) Status of obsessive compulsive disorder among Iranian college students in Kermanshah, Iran. J Hum Environ Health Promot. 1(4):213-219
10. Leininger M, Taylor Dyches T, Prater MA, Heath MA (2010) Teaching students with obsessive-compulsive disorder. Intervention in School and Clinic. 45(4):221-231

11. Huang J, Nigatu YT, Smail-Crevier R, Zhang X, Wang J (2018) Interventions for common mental health problems among university and college students: a systematic review and meta-analysis of randomized controlled trials. J Psychiatric Res. 107:1

12. Huz I, Nyer M, Dickson C, Farabaugh A, Alpert J, Fava M, Baer L (2016) Obsessive-compulsive symptoms as a risk factor for suicidality in US college students. J Adolesc Health. 58(4):481-484

13. Torres AR, Fontenelle LF, Shavitt RG, Hoexter MQ, Pittenger CH, Miguel EC (2017) Epidemiology, comorbidity, and burden of OCD. In Obsessivecompulsive disorder: phenomenology, pathophysiology, and treatment. Oxford University Press, Oxford

14. Safaralizadeh F, Bagheriyeh F (2014) The prevalence obsessive-compulsive disorder in students in Khoy University in 2013. IJPN. 2(2):13-21

15. Sulkowski ML, Mariaskin A, Storch EA (2011) Obsessive-compulsive spectrum disorder symptoms in college students. Journal of American College Health. 59(5):342-348

16. Lei X, Chen C, He Q, Chen C, Moyzis RK, Xue G, Chen X, Cao Z, Li J, Li H, Zhu B (2012) Sex determines which section of the SLC6A4 gene is linked to obsessive-compulsive symptoms in normal Chinese college students. J Psychiatric Res. 46(9):1153-1160

17. El-Gilany AH, Amro M, Eladawi N, Khalil M (2019) Mental health status of medical students: a single faculty study in Egypt. J Nervous Ment Dis. 207(5):348-354

18. Fineberg NA, Van Ameringen M, Drummond L, Hollander E, Stein DJ, Geller D et al (2020) How to manage obsessive-compulsive disorder (OCD) under COVID-19: a clinician's guide from the International College of Obsessive Compulsive Spectrum Disorders (ICOCS) and the Obsessive-Compulsive Research Network (OCRN) of the European College of Neuropsychopharmacology. Compr Psychiatry. 100:152174

19. Tanir Y, Karayagmurlu A, Kaya I, Kaynar TB, Türkmen G, Dambasan BN, Meral $Y$, Coşkun M (2020) Exacerbation of obsessive compulsive disorder symptoms in children and adolescents during COVID-19 pandemic. Psychiatry Research. 293:113363

20. Chakraborty A, Karmakar S (2020) Impact of COVID-19 on obsessive compulsive disorder (OCD). Iranian Journal of Psychiatry. 15(3):256-259

21. Foa EB, Huppert JD, Leiberg S, Hajcak G, Langner R, Kichic R, Hajcak G, Salkovskis PM (2002) The obsessive-compulsive inventory: development and validation of a short version. Psychological Assessment 14:485-496

22. Alsubaie SS, Almathami M, Abouelyazid A, Alqahtani MM, Alshehri W, Alamri A (2020) Prevalence of obsessive compulsive disorder: a survey with Southern Saudi Arabian samples. J Psychiatry Depress Anxiety 6:031

23. Hama R, Ahmed N (2018) Obsessive compulsive symptoms among students of Faculty of Medical Sciences and Faculty of Humanities Education in University of Sulaimani. J Sulaimani Med College. 8(4):299-305

24. Opakunle T, Aloba O, Opakunle O, Oyewole A, Osokoya O (2017) Prevalence and correlates of obsessive-compulsive symptoms in a sample of undergraduate clinical medical students in Osogbo, Southwestern Nigeria. Nigerian J Health Sci. 17(2):66

25. Abba-Aji A, Li D, Hrabok M, Shalaby R, Gusnowski A, Vuong W, Shireen S, Nkire N, Li XM, Greenshaw A, Israel V, Agyapong O (2020) COVID-19 pandemic and mental health: prevalence and correlates of new-onset obsessive-compulsive symptoms in a Canadian province. Int J Environ Res Public Health. 17(19):6986

26. Lai J, Ma S, Wang Y, Cai Z, Hu J, Wei NWJ, Du H, Chen T, Li R, Tan H, Kang LW, Yao L, Huang M, Wang H, Wang G, Liu Z, Hu S (2020) Factors associated with mental health outcomes among health care workers exposed to coronavirus disease 2019. JAMA Network Open 3(3):e203976

27. Wang C, Pan R, Wan X, Tan Y, Xu L, Ho C, Ho RC (2020) Immediate psychological responses and associated factors during the initial stage of the 2019 coronavirus disease (COVID-19) epidemic among the general population in China. Int J Environ Res Public Health. 17(5):1729

28. Magnavita N, Tripepi G, Di Prinzio R (2020) Symptoms in health care workers during the COVID-19 epidemic. A cross-sectional survey. Int J Environ Res Public Health 17(14):5218

29. Diagnostic and Statistical Manual of Mental Disorders and OCD | OCD-UK. Ocduk.org. 2020 [cited 5 October 2020]. Available from: https://www.ocduk. org/ocd/clinical-classification-of-ocd/dsm-and-ocd/ 
30. Pacheco J, Giacomin H, Tam W, Ribeiro T, Arab C, Bezerra I, Pinasco G (2017) Mental health problems among medical students in Brazil: a systematic review and meta-analysis. Revista Brasileira de Psiquiatria. 39(4):369-378

31. Zeng W, Chen R, Wang X, Zhang Q, Deng W (2019) Prevalence of mental health problems among medical students in China. Medicine 98(18):e15337

\section{Publisher's Note}

Springer Nature remains neutral with regard to jurisdictional claims in published maps and institutional affiliations.

Submit your manuscript to a SpringerOpen ${ }^{\odot}$ journal and benefit from:

- Convenient online submission

- Rigorous peer review

- Open access: articles freely available online

- High visibility within the field

- Retaining the copyright to your article

Submit your next manuscript at $\boldsymbol{\wedge}$ springeropen.com 